\title{
Differences between Female Subjects Practicing Pilates and Aerobics
}

\author{
Josipa Radas, Vinka Sesar and Gordana Furjan-Mandic \\ University of Zagreb, Faculty of Kinesiology, Zagreb, Croatia
}

\begin{abstract}
A B S T R A C T
The aim of this study was to establish if there are differences in strength between female subjects who practice Pilates and aerobics. Research was conducted on a sample of two groups, each consisting of 28 subjects, with tests being push-ups, "hundred" and wall squat hold. Differences between groups have been established by T-test for independent samples. Research has shown certain differences between aerobics and Pilates programs. Subjects who practice aerobics scored better results in all tests than subjects who practice Pilates. It can be concluded that aerobics program is much better for development of these types of strength. However, because this is not a representative sample that cannot be claimed.
\end{abstract}

Key words: program types, fitness, women

\section{Introduction}

Various forms of recreational forms of exercise are conducted in fitness centers. Most common types of group exercising are aerobics and Pilates, and the reason behind that is that there are simple activities which enable women to participate in this types of exercising without any problems and without previously acquired knowledge. Contemporary aerobics enables development and conservation of vital functional abilities which are a requirement for healthy life, and therefore enable for every individual to improve their health (Furjan-Mandić, 2007). Pilates method is a system of stretching and strength exercises which strengthens and shapes muscles, corrects posture, gives flexibility and balance, unifies mind and body, and perfects body figure (Siler, 2003). Exercises for strength development are present in both forms of exercising, but in a different way. In aerobics, it is conducted through a dynamic type of training, in Pilates through a static type of training. Final goal of both types of exercising is strengthening and balancing of the body, minimizing stress and increasing endurance through exercises, as well as enabling a person to feel better and to confront everyday challenges more easily. There is a numerous studies from areas of aerobics and Pilates, and on their impact on certain abilities (Nikić \& Milenković, 2013; Marques et al., 2011; Kloubec, 2010; Dorado, Calbet, Lopez-Gordillo, Alayon,
\& Sanchis-Moysi, 2012; Kloubec \& Banks, 2004). On the other hand, scientific studies of strength between Pilates and aerobics programs are seldom, and for that reason, the goal of this research was to determine if there are differences in strength between women who practice Pilates and aerobics.

\section{Methods}

\section{Sample of subjects}

Sample of subjects involved in this research consists of two groups of exercisers (28 female subjects in each group) in a fitness center in Zagreb. One group of women practices Pilates, and other practices aerobics. Age of exercisers is from 20 to 50 years, and duration of involvement in each activity ranges from 1 to 4 years. All of them have in common that they exercise regularly, 3 times a week for 60 minutes, trainings are quite intensive and require greater fitness and motor readiness.

\section{Sample of variables}

Sample of observed variables consists of following tests for evaluation of relative repetitive and static strength: test for evaluation of arm and shoulder region strength (push-ups), test for evaluation of abdomen strength ("hundred") and test for evaluation of leg strength (wall squat hold)

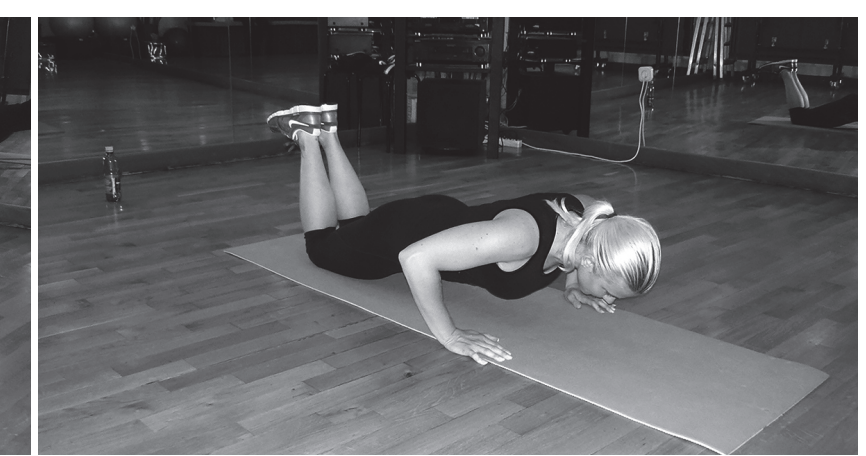

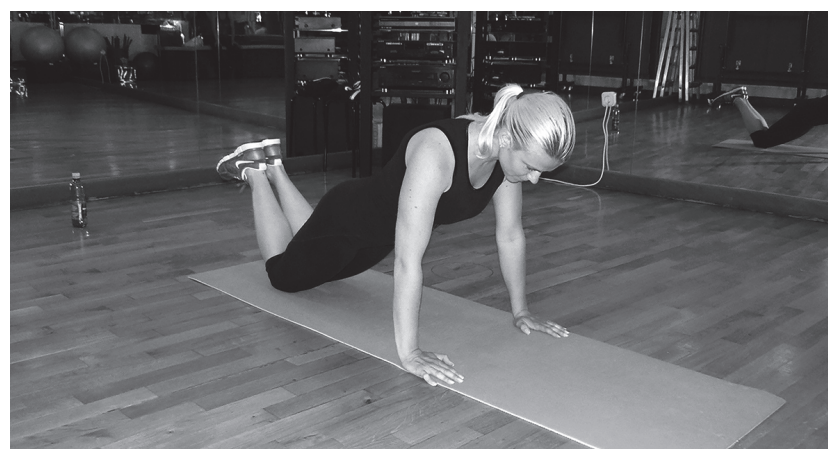

Figure 1. Push-ups test 


\section{Test descriptions}

Test for evaluation of arm and shoulder region strength push ups

Subjects performed push-ups in frontal hold and on knees (Figure 1). From frontal hold on knees, with raised lower legs, palms are placed in shoulder width, as the subject inhales, the body is lowered into a push up position. As the subject exhales, body returns back to the starting position. Head is straight in extension of the spine, subject leans on knees above patella, and lumbar part of spine should not be arched. Exercise was performed until exhaustion, with as much repetitions as possible. Relative repetitive motor strength was measured with this test

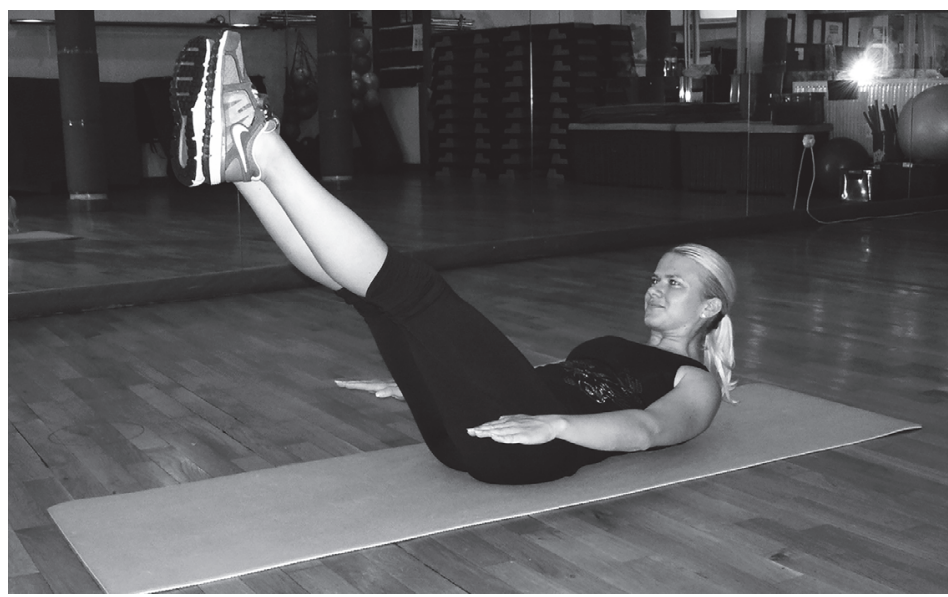

Figure 2. "Hundred" test

Test for evaluation of abdomen strength - "hundred"

From lying position on back, subject raises head upwards, so the support is on lower part of scapula (Figure 2). Simultaneously, legs are raised and extended diagonally forward, with hands extended beside the body in abdomen height. Exercise was performed until exhaustion, as long as possible. Static strength of abdomen was measured with this test.

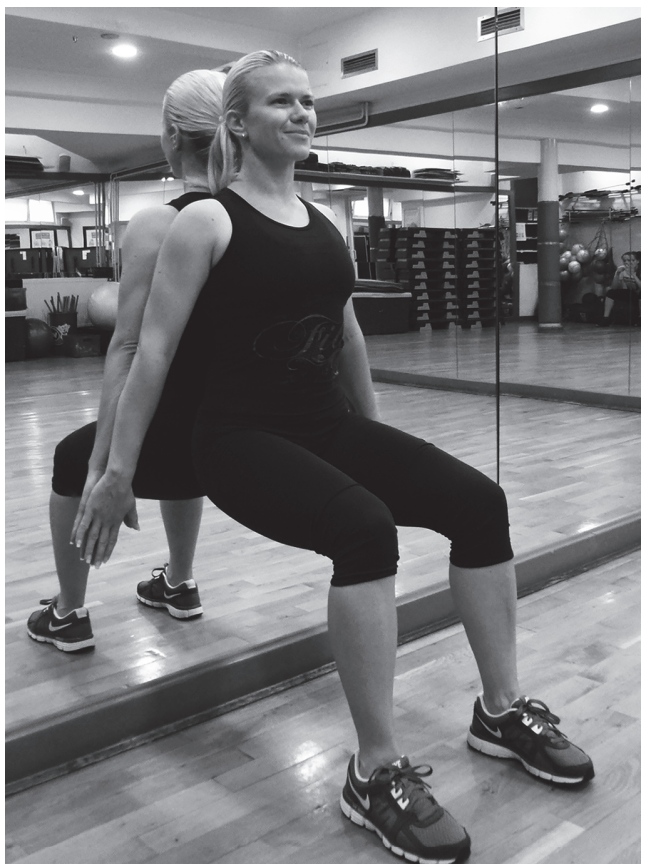

Figure 3. Wall squat hold test

Test for evaluation of leg strength -wall squat hold

Subject leans on the wall with knees and hips bent under $90^{\circ}$ (Figure 3). Hands are extended beside the body. Head is straight in extension of the spine. Exercise was performed until exhaustion, as long as possible. Static leg strength was measured with this test.

\section{Collection of data}

Data was acquired during classes of Pilates and aerobics.
For the purpose of satisfying criteria of objectivity of measuring instrument, measuring of all subjects was performed by the examiner personally. Manner of execution of tasks was explained and demonstrated to subjects. General goal of the research was also briefly explained.

\section{Data processing methods}

Basic descriptive parameters (arithmetic mean, standard deviation, minimum and maximum of results, skewness and 
kurtosis) have been calculated by descriptive analysis of data. Differences between groups of subjects have been determined by $\mathrm{T}$-test for independent samples.

\section{Results}

Descriptive statistics results display average values and standard deviations of variable push-ups, "hundred" and wall squat hold.

Table 1. Basic descriptive parameters of variables of pilates group

\begin{tabular}{lccccccc}
\hline & AM & SD & MIN & MAX & R & Skewness & Kurtosis \\
\hline PUSH-UPS & 19,14 & 8,08 & 10,00 & 33,00 & 23,00 & 0,34 & $-1,45$ \\
"HUNDRED" & 1,28 & 0,58 & 0,41 & 2,53 & 2,12 & 0,57 & $-0,19$ \\
SQUAT & 1,14 & 0,72 & 0,19 & 2,57 & 2,38 & 0,50 & $-0,94$ \\
\hline
\end{tabular}

Legend: AM-arithmetic mean, SD-standard deviation, MIN-minimal value, MAX-maximal value, R-total range, skewness-asymmetry distribution coefficient, kurtosis-curvature distribution coefficient

In the first part of statistical data processing, basic descriptive parameters of variables of strength between Pilates and aerobics are displayed. Results show that subjects who perform aerobics had better results in all three tests (Table 1 and 2), and that the biggest difference was perceived in the push-ups test.

Table 2. Basic descriptive parameters of aerobics group

\begin{tabular}{lccccccc}
\hline & AM & SD & MIN & MAX & R & Skewness & Kurtosis \\
\hline PUSH-UPS & 23,57 & 7,16 & 10,00 & 37,00 & 27,00 & $-0,07$ & $-0,73$ \\
"HUNDRED" & 1,52 & 0,56 & 0,40 & 2,52 & 2,12 & 0,27 & $-0,50$ \\
SQUAT & 1,51 & 0,75 & 0,40 & 3,02 & 2,62 & 0,49 & $-0,51$ \\
\hline
\end{tabular}

Legend: AM-arithmetic mean, SD-standard deviation, MIN-minimal value, MAX-maximal value, R-total range, skewness-asymmetry distribution coefficient, kurtosis-curvature distribution coefficient

Table 3 displays statistically significant difference in test for evaluation of arm and shoulder region strength - push-ups, between individual groups on the level of significance $p=0.03$.
Data indicates that subjects who perform aerobics have better results, and therefore higher strength in upper body part.

Table 3. T-test for independent samples results between pilates and aerobics group

\begin{tabular}{lccccccccccc}
\hline & $\mathrm{AMp}$ & $\mathrm{AMa}$ & $\mathrm{T}$ & $\mathrm{df}$ & $\mathrm{p}$ & $\mathrm{Np}$ & $\mathrm{Na}$ & $\mathrm{SDp}$ & $\mathrm{SDa}$ & $\mathrm{F}$-var & $\mathrm{p}$-var \\
\hline PUSH-UPS & 19,14 & 23,57 & $-2,16$ & 54 & 0,03 & 28 & 28 & 8,08 & 7,16 & 1,27 & 0,53 \\
"HUNDRED" & 1,28 & 1,52 & $-1,57$ & 54 & 0,12 & 28 & 28 & 0,58 & 0,56 & 1,06 & 0,86 \\
SQUAT & 1,14 & 1,51 & $-1,89$ & 54 & 0,06 & 28 & 28 & 0,72 & 0,75 & 1,09 & 0,82 \\
\hline
\end{tabular}

Legend: AMp-arithmetic mean pilates, AMa-arithmetic mean aerobics, t-value, df-degrees of freedom, p-error, Npnumber of pilates subjects, Na-number of aerobics subjects, SDp-standard deviation pilates, SDa-standard deviation aerobics, F-var-value for testing significance of differences of variance of groups, p-var-error which claims that variance difference is statistically significant

\section{Discussion}

Relative repetitive arm and shoulder region strength was measured in the test push-ups, aerobics subjects have attained higher number of repetitions and because of that arithmetic mean is larger. Standard deviation is smaller, which indicates larger homogeneity of results, and respectively, that subjects have more equal upper body strength. Pilates subjects are somewhat weaker, and result homogeneity is smaller. In test "hundred", for evaluation of abdomen static strength, differences in strength are not very big, although aerobics subjects attained slightly better results, which indicates that they have stronger abdominal muscles. Standard deviations in both groups are not large, and that indicates homogeneity of results, an respectively, equal abdomen strength in both groups separately. This test was measured on time (as long as possible), which means that aerobics subjects have a slightly better endurance. Third test used was wall squat hold, where static leg strength was measured. Aerobics group had better time values and a larger arithmetic mean. Although Pilates group had lower results, standard deviation is smaller, which indicates a higher result homogeneity, and respectively, that Pilates subjects have smaller differences between themselves in leg strength evalua- tion test (although inferior to subjects who perform aerobics). This test was also measured on time, and aerobics subjects have shown greater endurance.

Goal of this research was to establish if there are differences between aerobics and Pilates in regard to strength of women. Results have shown that there are certain differences between these two programs. Acquired data in push-ups test has shown that there are statistically significant differences, while "hundred" and wall squat hold tests have shown that there are no statistically significant differences, although differences do exist. It could be concluded that aerobics program is much more suitable for development of these types of strength. However, because this was not a representative sample, that cannot be claimed. It can only be assumed that this is a better program for development of strength and other motor and functional abilities.

This is another study which displays certain differences in programs of aerobics and Pilates. Various other programs are also offered in fitness centers. All these programs have a positive impact on health and psychophysical state of a person. It is important that a person selects a program that will satisfy his/her needs and with which health goals will be achieved. That should also be our primary task. 


\section{R E F E R E N C E S}

Dizdar, D. (2006). Quantitative Methods. Zagreb: Faculty of Kinesiology University of Zagreb.

Dorado, C., Calbet, J.A.L., Lopez-Gordillo, A., Alayon, S., \& Sanchis-Moysi, J. (2012). Marked Effectsof Pilates on the Abdominal Muscles: A Longitudinal Magnetic Resonance Imaging Study. Medicine \&Science in Sports \& Exercise, 44(8), 1589-1594.

Furjan-Mandić, G. (2007). Methods of Aerobics. Zagreb: Faculty of Kinesiology University of Zagreb.

Kloubec, J., \& Banks, A.L. (2004). Pilates and Physical Education: A Nature Fit. The Journal of Physical Education, Recreation\& Dance, 75(4), 34-51.

Kloubec, J.A. (2010). Pilates for improvement of muscle endurance, flexibility, balance, and posture. Journal of
Strength \& Conditioning Research, 24(3), 661-667.

Marques, E.A., Wanderley, F., Machado, L., Sousa, F., Viana, J.L., Moreira-Gonçalves, D., Moreira, P., Mota, J., Carvalho, J. (2011). Effects of resistance and aerobic exercise on physical function, bone mineral density, OPG and RANKL in older women. Exp Gerontol, 46(7), 524-32.

Nikić, N., \& Milenković, D. (2013). Efficiency of step aerobics program in younger women. Acta Medica Medianae, 52(3), 25-34.

Papo, V. (2009) Influence of aerobics on repetitive strength increase in women (thesis paper). Zagreb: Faculty of Kinesiology University of Zagreb.

Siler, B. (2003). Pilates Body. Biovega, Zagreb.

\author{
J. Radas \\ University of Zagreb, Faculty of Kinesiology, Horvaćanski zavoj 15, 10000 Zagreb, Croatia \\ e-mail:josipa.radas@kif.hr
}

